increase of $0.1 \%$ from baseline in the usual care group $(P=0.019)$. The intervention group compared with the usual care group had small but statistically significant improvements in the secondary measures of fasting blood glucose, systolic and diastolic blood pressure, total cholesterol, LDL, serum triglycerides, self-reported medication adherence and self-care activities. Between-group differences in changes in the secondary measures of HDL and body mass index were not significant.

Conclusions The enhanced patient clinical outcomes as a result of pharmacist-led pharmaceutical care in an outpatient diabetes clinic in the present study demonstrate the value of an enhanced clinical pharmacy service in improving diabetes care and achieving the desired therapeutic outcomes for patients with type 2 diabetes.

No conflict of interest.

\section{CPC-120 RANITIDINE-INDUCED SYSTEMIC HYPERSENSITIVITY REACTION: A CASE REPORT}

doi:10.1136/ejhpharm-2013-000276.577

'M Geneste, 'S Bourget, 'P Brun, 'I Dufrene, 'H Hida. 'Hospital, Pharmacy, Valence Cedex 09, France; ${ }^{2}$ Hospital, Pneumology, Valence Cedex 09, France

Background Ranitidine is a histamine-2-receptor antagonist (antiH2) widely used with an excellent safety record. It's a drug included in the premedication for several chemotherapy regimens.

Purpose To report a case of hypersensitivity to ranitidine.

Materials and Methods Case report, literature review.

Results A 68-year-old man was being followed at hospital for management of metastatic lung carcinoma. A third-line treatment with weekly paclitaxel had been decided. The usual premedication includes intravenous ondansetron, ranitidine, dexchlorpheniramine and methylprednisolone. The patient's anamnesis hadn't reported any allergic events.

During the first course, the patient presented pruritus 5 minutes after ondansetron and ranitidine injections. Hypotension and warmth occurred despite the administration of dexchlorpheniramine. $120 \mathrm{mg}$ of methylprednisolone resolved the hypersensitivity completely before the patient received paclitaxel, without further event.

During the next course, ondansetron was replaced by metoclopramide. During the ranitidine infusion the patient presented sweats, hypotension and bronchospasm. Ranitidine infusion was stopped and methylprednisolone overcame the reaction. The patient's condition allowed paclitaxel administration although he refused dexchlorpheniramine.

The need for antiH2 and the most appropriate premedication for the next courses were discussed by the clinician and pharmacist. Hypersensitivity reactions are reported in ranitidine's SPC with an estimated rare frequency and also in the literature review. A case also reported a cross-reaction between antiH2 and other antihistamines [1], while another author excluded it [2].

As no allergic investigation has been performed, all antihistamines have been removed as a precaution. For subsequent courses the premedication included metoclopramide $10 \mathrm{mg}$ and methylprednisolone $80 \mathrm{mg}$. No other incidents have been reported. This search didn't formally establish the need for antiH2 in paclitaxel premedication.

Conclusion: This case has been reported to the pharmacovigilance centre and reminds clinicians that even commonly used and generally well-tolerated substances can cause serious side effects.

\section{References}

1. Thurot-Guillou $\mathrm{C}$ et al, Anaphylactic reaction to ranitidine and dexchlorpheniramine.

2. Aouam K et al, Severe ranitidine-induced anaphylaxis: a case report and literature review.

No conflict of interest.

\section{CPC-121 REPORT AFTER ONE YEAR USING OF FINGOLIMOD, THE FIRST ORAL TREATMENT FOR MULTIPLE SCLEROSIS: ANALYSIS OF PATIENTS IN A NEUROLOGY UNIT}

doi:10.1136/ejhpharm-2013-000276.578

${ }^{1} \mathrm{C}$ Golé, ${ }^{2 A}$ Darque, ${ }^{3} \mathrm{~A}$ Rico, ${ }^{3} \mathrm{~J}$ Pelletier, 'P Pisano, ${ }^{2} \mathrm{~S}$ Gensollen. 'Hôpital La Timone, Pharmacy, Marseille, France; ${ }^{2}$ Hôpital La Conception, Pharmacy, Marseille, France, ${ }^{3}$ Hôpital La Timone, Neurology, Marseille, France

Background Multiple sclerosis (MS) is in Europe the most common neurological disease starting between the ages of 20 and 40 years. It affects approximately 2.5 million people worldwide and is the first cause of non-traumatic disability for young people. Management of this disease has for a long time been limited to treatment of relapses. However, in recent years, significant progresses have been made in the treatment with the appearance of, among others, fingolimod for relapsing-remitting MS in March 2011 in the European Union.

Purpose To observe the impact of fingolimod in the care of patients, and make an assessment of practise in the neurology unit (Professor Pelletier, La Timone hospital, Marseille) one year after fingolimod was approved for use.

Materials and Methods We noted treatment interruptions and their causes, and analysed benefits and side effects reported by patients treated with fingolimod for more than three months. Data collection was based on meetings or telephone interviews with patients and on information taken from medical records.

Results 143 patients started treatment with fingolimod between March 2011 and October 2012, 51 in the last three months. Our analysis was performed on 92 patients, and included 19 meetings and 20 telephone interviews. Four definitive treatment interruptions were identified: three for disease progression (relapses) and one hepatic cytolysis. We also noted two temporary discontinuations for tuberculosis contagion and hives. Preliminary results show that the clinical and biological tolerance was satisfactory in most cases. Furthermore, absence of relapse or improvements in motor status and tiredness were noted by the majority.

Conclusions Fingolimod has changed the management of patients with MS, and many of them have reported an improvement in their quality of life and feel side effects to be acceptable. The imminent arrival of other oral agents should result in clarification of the role of each in the strategy, and might be the subject of comparative studies.

No conflict of interest.

\section{CPC-122 RISK FACTORS IN THE INCIDENCE OF CHEMOTHERAPY- INDUCED EMESIS}

doi:10.1136/ejhpharm-2013-000276.579

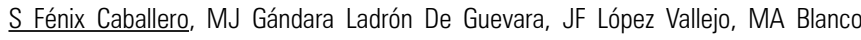
Castaño, C Palomo Palomo, C Martinez Diaz. Puerto Real Universitary Hospital, Pharmacy Department, Puerto Real, Spain

Background Chemotherapy-induced nausea and vomiting (CINV) are the most common side effects after the administration of anticancer drugs. CINV appears in a variable percentage of patients, depending on the cytostatic agent and patients' risk factors.

Purpose The aim of this study was to evaluate the effect of the risk factors on the incidence of emesis after the administration of the first cycle of chemotherapy.

Materials and Methods A literature search was conducted for articles addressing the risk factors in CINV. Younger age, female sex, history of motion sickness or pregnancy-induced vomiting, radiotherapy and anxiety/depression were included. A history of alcohol intake was considered a protective factor and it was graded as none, mild (1-5 drinks/month), moderate (6-14) or high (>14) consumption. The impact on complete response (CR) of those risk factors for 
Abstract CPC-122 Table 1

\begin{tabular}{|c|c|c|c|c|c|}
\hline Risk factors & Patients & CR (N, \%) & Non-CR (N, \%) & $\begin{array}{l}\text { Risk reduction } \\
\text { CR vs. Non-CR }\end{array}$ & $\begin{array}{l}\text { Statistical difference (SD) or Non-significant } \\
\text { difference (NSD) }\end{array}$ \\
\hline $\begin{array}{l}\text { Age }(n=30) \\
\text { Age }>75 \\
\text { Age } 51-74 \\
\text { Age } 31-50\end{array}$ & $\begin{array}{l}3 \\
21 \\
6\end{array}$ & $\begin{array}{l}3(100 \%) \\
16(76.2 \%) \\
2(33.3 \%)\end{array}$ & $\begin{array}{l}0 \\
5(23.8 \%) \\
4(66.7 \%)\end{array}$ & $\begin{array}{l}100 \% \\
52.4 \% \\
33.3 \%\end{array}$ & SD between all subgroups. \\
\hline $\begin{array}{l}\text { Sex }(n=30) \\
\text { Female } \\
\text { Male }\end{array}$ & $\begin{array}{l}14 \\
16\end{array}$ & $\begin{array}{l}8(57.1 \%) \\
13(81.2 \%)\end{array}$ & $\begin{array}{l}6(42.9 \%) \\
3(18.8 \%)\end{array}$ & $\begin{array}{l}14.2 \% \\
62.4 \%\end{array}$ & NSD \\
\hline History of motion sickness & 4 & $3(75 \%)$ & $1(25 \%)$ & $50 \%$ & \\
\hline Pregnancy-induced vomiting & 4 & $3(75 \%)$ & $1(25 \%)$ & $50 \%$ & \\
\hline Radiotherapy & 3 & $2(66.7 \%)$ & $1(33.3 \%)$ & $33.3 \%$ & \\
\hline Anxiety/depression & 6 & $3(50 \%)$ & $3(50 \%)$ & - & \\
\hline $\begin{array}{l}\text { Alcohol intake history }(\mathrm{n}=30) \\
\text { None } \\
\text { Mild }(1-5) \\
\text { Moderate }(6-14) \\
\text { High }(>14)\end{array}$ & $\begin{array}{l}19 \\
9 \\
1 \\
1\end{array}$ & $\begin{array}{l}12(63.2 \%) \\
6(66.7 \%) \\
1(100 \%) \\
1(100 \%)\end{array}$ & $\begin{array}{l}7(36.8 \%) \\
3(33.3 \%) \\
0 \\
0\end{array}$ & $\begin{array}{l}26.4 \% \\
33.4 \% \\
100 \% \\
100 \%\end{array}$ & $\begin{array}{l}\text { SD between zero and mild consumption vs. } \\
\text { moderate and high. }\end{array}$ \\
\hline
\end{tabular}

CINV was investigated. CR was defined as no emetic episodes during the overall 5-day study period. Patients' risk factors were recorded before chemotherapy infusion. All patients received intravenous 5HT3-receptor antagonists before chemotherapy infusion and a two-drug combination (metoclopramide and dexamethasone) on the following four days. Patients kept a diary to report CINV during the 5-day period. Univariate analyses were performed to determine the risk factors significantly associated with emesis after the first cycle of chemotherapy. Risk reduction between CR and non-CR results were calculated. The statistical significance among risk-factor subgroups was also evaluated in order to assess the extent of influence of each one.

Results A total of 30 patients were evaluated. The incidence of emesis is summarised in the table.

Conclusions The younger the patient the less emetic control there was. Although the risk was higher in women, this difference was not significant. None or minor consumption of alcohol had significantly higher risk of emesis than moderate or high. A multivariable analysis may be performed to confirm the relationship between risk factors and CINV.

No conflict of interest.

\section{CPC-123 RISPERIDONE AND SUSPECTED ANGIONEUROTIC OEDEMA: CONTRIBUTION OF MULTIDISCIPLINARY CARE}

doi:10.1136/ejhpharm-2013-000276.580

${ }^{1} \mathrm{M}$ Agullo, ${ }^{2} \mathrm{~S}$ Duffy, ${ }^{3} \mathrm{~A}$ Du Thanh, ${ }^{1} \mathrm{M}$ Villiet, ${ }^{1} \mathrm{~S}$ Hansel Esteller. ${ }^{1} \mathrm{CHRU}$ of Montpellier Lapeyronie Hospital, Pharmacy, Montpellier, France; ${ }^{2} \mathrm{CHRU}$ of Montpellier Lapeyronie Hospital, Emergencies, Montpellier, France; ${ }^{3} \mathrm{CHRU}$ of Montpellier Saint Eloi Hospital, Dermatology Regional Reference Center for Bradykinin Angioedema, Montpellier, France

Background Psychotropic drugs may cause cutaneous eruptions with various degrees of severity ranging from urticaria to 'angioedema' (AE). Respiratory tract obstruction needs emergency care.

Purpose To report on a patient who developed facial AE following treatment with risperidone.

Materials and Methods An 85-year-old woman was admitted to the emergency department (ED) for acute respiratory failure 24 hours after risperidone was introduced.

Results She presented macroglossia, dyspnoea and oedema of the soft palate, unresolved with antihistamines and steroids. In the ED, risperidone was reintroduced for agitation. It was immediately followed by severe dyspnoea, oedema of the tongue and uvula requiring admission to the intensive care unit. Risperidone imputability was suspected after a review of the literature. The Regional Reference Centre for Bradykinin AE (BAE) was consulted. Allergic oedema caused by risperidone but not BAE was concluded (delay of occurrence, absence of real BAE case with risperidone). Risperidone was stopped, the patient was monitored and treated with the optimal dose of steroids and antihistamines. Oedema resolved in 48 hours and patient went back home without sequelae. Naranjo evaluation scored 9 , so it was highly probable that oedema was linked to the drug.

Conclusions AE can result in laryngeal oedema and fatal airway obstruction. When differential diagnoses are eliminated, AE is classified into allergic/pseudo-allergic or bradykinin-related (hereditary or acquired with angiotensin-converting enzyme inhibitors and sartans). The mechanism of drug-induced BAE seems to be mediated by increased plasma bradykinin levels, because these drugs reduce its breakdown.

$\mathrm{AE}$ has been reported to occur with antipsychotics like risperidone, but these drugs probably produce histaminergic AE, not BAE. In our case, this hypothesis must be ruled out with cutaneous allergology prick tests with risperidone.

Diagnosis of BAE can be difficult. Clinical signs and oedema resistant to conventional treatments have led to suspicion of BAE. French Reference Centres can improve and optimise detection and treatment of these orphan diseases and limit use of expensive drugs (e.g. icatibant: 6,300 US dollars per patient).

No conflict of interest.

\section{CPC-124 RIVAROXABAN OR CONVENTIONAL THROMBOPROPHYLAXIS AFTER MAJOR ORTHOPAEDIC SURGERY IN ROUTINE PRACTISE: INFLUENCE OF CO- MEDICATIONS ON OUTCOMES IN THE XAMOS STUDY}

doi:10.1136/ejhpharm-2013-000276.581

${ }^{1} \mathrm{R}$ Kreutz, ${ }^{2} \mathrm{~S}$ Haas, ${ }^{3} \mathrm{G}$ Holberg, ${ }^{4} \mathrm{MR}$ Lassen, ${ }^{5} \mathrm{LG}$ Mantovani, ${ }^{3} \mathrm{~A}$ Schmidt, ${ }^{6} \mathrm{AGG}$ Turpie. ${ }^{1}$ Charité, Department of Clinical Pharmacology and Toxicology, Berlin, Germany; 2Institute for Experimental Oncology and Therapy Research, Technical University of Munich, Munich, Germany; ${ }^{3}$ Bayer Healthcare AG, GMA, Berlin, Germany; ${ }^{4}$ Glostrup Hospital University of Copenhagen, Clinical Trial Unit, Copenhagen, Denmark; ${ }^{5}$ Federico II University of Naples, CIRFF Center of Pharmacoeconomics, Naples, Italy; ${ }^{6} \mathrm{Hamilton}$ Health Services, Department of Medicine, Hamilton Ontario, Canada

Background Rivaroxaban, a direct Factor Xa inhibitor, has been shown to be more effective in preventing venous thromboembolism than enoxaparin regimens, with a similar safety profile, in patients undergoing hip or knee arthroplasty (the phase III RECORD studies). Rivaroxaban is approved for this indication worldwide.

Purpose To examine the effectiveness and safety of rivaroxaban for thromboprophylaxis in routine clinical practise and the impact of selected co-medication use on outcomes. 